\title{
STENCIL SCREENS FOR FINE-LINE PRINTING
}

\author{
STEWART G. STALNECKER, JR. \\ Microcircuit Engineering Corporation, Mount Holly, New Jersey 08060, U.S.A.
}

(Received June 11, 1979)

\begin{abstract}
During the past decade, the thick film process has become a viable technology for the production of numerous varieties of electronic circuits. Improvements in the quality of the substrates, the thick film inks, and the manufacturing equipment have all been significant. In addition, the quality of the stencil screens has also been improved to aid the process. New types of mesh material, improved emulsion systems and better control of the screen parameters have all been realized. These refinements in the screen making materials and processes have all contributed to the feasibility for printing complex resistor and conductor networks, hybrid circuits, multilayer arrays, and sophisticated watch and display patterns.

This paper will present the critical parameters of the screen mesh materials and compare the characteristics of the screen mesh materials and compare the characteristics of the nylon, polyester, stainless steel and metalized polyester fabrics. A new fine-wire 325 mesh stainless steel will be discussed and the significant impact on the technology of fine-line printing will be illustrated. In addition, recent developments in screen emulsions will be offered and pictures of fine-line patterns will be shown.
\end{abstract}

\section{INTRODUCTION}

The preparation of stencil screens for printing thick film circuits has been presented in numerous articles. $^{1,2,3}$ In particular, the screen frame has been designated to be an aluminum casting which is finished so that both surfaces are flat and parallel. The design and quality of the screen frame is important for achieving a suitable support for the screen mesh material. This support must be rigid and have a uniform flat surface to which the screen fabric is mounted. However, the screen mesh itself and the stencil preparation are the two most critical factors of the screen making process which will be examined in detail.

\section{MESH}

Techniques for mounting the screen mesh to the frame are well documented. ${ }^{1}$ Epoxy adhesives are used primarily to allow the screen maker to properly adhere the mesh material to the screen frame. The mesh must be applied with adequate tension and at the proper angle. Epoxy materials with high shear strength assure that the mesh will remain fixed to the screen frame. Movement of the mesh on the frame will result in pattern alignment and/or distortion problems.
When printing fine-line patterns, the selection of the screen mesh deserves careful consideration. For clarification, the term "fine-line" will be used to designate patterns which have line widths in the range of 50 to 127 microns. In order to transfer a particular composition or paste material through a screen, the size of the mesh openings and the number of threads per given length or area are important. Screen fabrics with larger thread diameters pose a serious problem since the threads will block the small openings in the screen stencil and restrict the paste from passing through the screen. The overall suitability of a particular screen fabric may be evaluated by comparing the physical parameters of the various mesh materials, such as the mesh count, wire or filament diameter, mesh opening, mesh thickness, and the percentage of open area.

These parameters are presented in Table I for some of the most commonly used fabrics with a mesh count above 280 openings per lineal inch.

It should be noted that the published data for the mesh specifications does not always agree with the actual measurements. In particular, the measured weave thickness for some of the synthetic materials was found to deviate considerably from the manufacturer's literature. It was also discovered that the actual mesh thickness figures varied between manufacturers for fabric with the same mesh count and filament diameter. Therefore in Table I, the 
TABLE I

Specifications for fine-mesh fabrics used in making stencil screens

\begin{tabular}{lllll}
\hline $\begin{array}{l}\text { Mesh } \\
\text { count } \\
\text { material }\end{array}$ & $\begin{array}{l}\text { Wire or } \\
\text { thread } \\
\text { diameter } \\
\text { (microns) }\end{array}$ & $\begin{array}{l}\text { Mesh } \\
\text { opening } \\
\text { (microns) }\end{array}$ & $\begin{array}{l}\text { Weave } \\
\text { thickness } \\
\text { (microns) }\end{array}$ & $\begin{array}{l}\text { Open } \\
\text { Area } \%\end{array}$ \\
\hline 280/SS & 30 & 61 & $76(\mathrm{~m}, \mathrm{p})$ & 45 \\
280-S/Nyl & 33 & 58 & $51(\mathrm{~m})$ & 45 \\
280-W/Dac & 33 & 53 & $56(\mathrm{~m})$ & 34 \\
280-HD/Dac & 41 & 46 & $66(\mathrm{~m})$ & 25 \\
280-T/M.P. & 37 & 54 & $65(\mathrm{p}), 55(\mathrm{~m})$ & 32 \\
300/SS & 32 & 56 & $71(\mathrm{p})$ & 41 \\
306-S/Nyl & 30 & 53 & $44(\mathrm{~m})$ & 41 \\
305-T/Dac & 33 & 51 & $65(\mathrm{p}), 57(\mathrm{~m})$ & 37 \\
305-T/M.P. & 38 & 47 & $65(\mathrm{p})$ & 29 \\
325/SS & 28 & 51 & $71(\mathrm{~m}, \mathrm{p})$ & 42 \\
330-S/Nyl & 30 & 46 & $47(\mathrm{~m})$ & 37 \\
330-T/Dac & 33 & 43 & $62(\mathrm{p}), 61(\mathrm{~m})$ & 31 \\
330-T/M.P. & 38 & 31 & NA & 23 \\
& & & & \\
400/SS & 25 & 38 & $56(\mathrm{~m}, \mathrm{p})$ & 36 \\
380-S/Nyl & 30 & 35 & $48(\mathrm{~m})$ & 30 \\
390/Dac & 33 & 32 & $55(\mathrm{~m})$ & 24 \\
390-T/M.P. & 38 & 31 & NA & 23 \\
\hline
\end{tabular}

$(\mathrm{p})=$ published value $;(\mathrm{m})=$ measured value $; \mathrm{NA}=$ Not Available; SS - Stainless Steel; Dac - Dacron (Polyester); Nyl - Nylon; M.P. - Metalized Polyester.

published $(\mathrm{p})$ and measured $(\mathrm{m})$ values for the mesh weave thickness have been presented. Stainless steel mesh has maintained its popularity for fine-line stencil screens in the United States for the following reasons:

a) High stability - allows for excellent registration and optimum pattern definition.

b) Large mesh openings - less blockage and better paste transfer than with synthetics.

c) Smaller wire diameters - less interference with the stencil image.

d) Highest percentage of open area - most evident when comparing fabrics with a mesh count of 325 and higher.

As shown in Table I, the synthetic fabrics do not compare well with the stainless steel materials.

Therefore, only stainless steel wire cloth was employed for preparing the fine-line screens for this study. To minimize the interference between the mesh wires and the openings in the stencil, a series of screens was prepared utilizing only small diameter wire cloth materials which were readily available. The range of wire diameters selected for the study was chosen to
TABLE II

Stainless steel mesh for fine-line stencil screens

\begin{tabular}{lllll}
\hline $\begin{array}{l}\text { Mesh } \\
\text { count }\end{array}$ & $\begin{array}{l}\text { Wire } \\
\text { diameter } \\
\text { (microns) }\end{array}$ & $\begin{array}{l}\text { Mesh } \\
\text { opening } \\
\text { (microns) }\end{array}$ & $\begin{array}{l}\text { Weave } \\
\text { thickness } \\
\text { (microns) }\end{array}$ & $\begin{array}{l}\text { Open } \\
\text { area \% }\end{array}$ \\
\hline 230 & 28 & 76 & 70 & 54 \\
280 & 30 & 61 & 76 & 45 \\
325 & 28 & 51 & 71 & 42 \\
325 & 23 & 55 & 53 & 51 \\
400 & 25 & 38 & 56 & 36 \\
\hline
\end{tabular}

be 25 to 30 microns. Table II lists the physical parameters of the wire cloth which was investigated.

The first series of test samples was prepared with four images on each screen. All four images were made from the same test pattern which is illustrated in Figure 1. The emulsion thickness of the stencil on each screen was approximately 15 microns.

The only difference between the four images on 


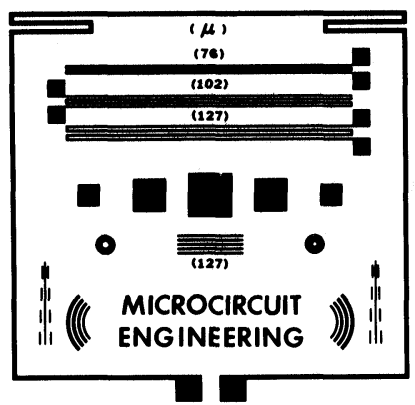

FIGURE 1 Test pattern for fine-line screens.

each screen was the orientation of the pattern to the mesh weave, e.g. $22 \frac{1}{2^{\circ}}, 30^{\circ}, 45^{\circ}$ and $90^{\circ}$.

Figure 2 illustrates the effect of the mesh orientation for a series of images applied to a 325 mesh screen (wire diameter of 28 microns). For comparison, the same image was exposed at the four different angles on four other screen meshes. In all cases, the emulsion thickness was approximately the same (10-15 microns) and the exposure time for each image was 3 minutes. The results are shown in Figures 3, 4, 5, and 6 .

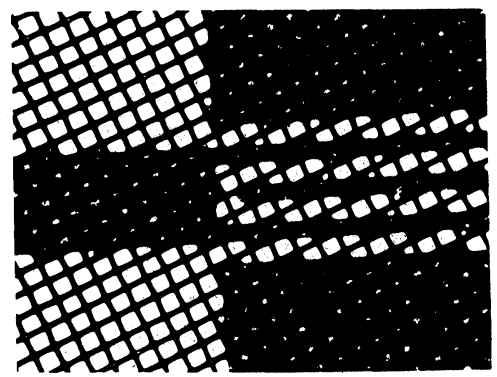

a) $22 \frac{1}{2^{\circ}}$

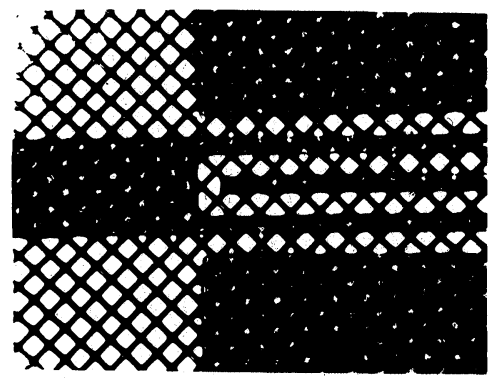

c) $45^{\circ}$
The alignment of the image to the screen mesh was very critical for the $90^{\circ}$ orientation as illustrated in print "d" of each figure. In most cases, it would be very desirable to utilize the total mesh openings on the screen. However, there are several problems which are unavoidable when trying to achieve this optimum condition.

1) The image lines must fall directly over the mesh openings (see Figure 2-d and Figure 3-d).

2) The mesh must be stretched and mounted so that the wires are very straight and parallel (no stair stepping as in Figure 4-d).

3) The size of the mesh openings in the screen must not vary.

4) The emulsion must not bridge between the stencil openings and the mesh wires (see Figure 5-d).

For these reasons, the pattern orientation to the mesh should be evaluated thoroughly prior to imaging the screen. From the illustrations presented in Figures $2-6$, it appears that the $45^{\circ}$ angle may be most desirable when fabricating screens with 76 micron line widths. However, for 102 or 127 micron lines, one of the other mesh-to-pattern orientations may be more satisfactory.

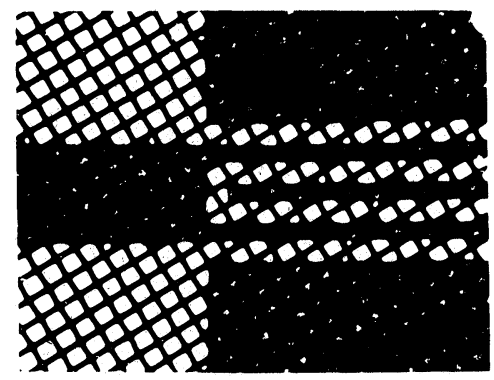

b) $30^{\circ}$

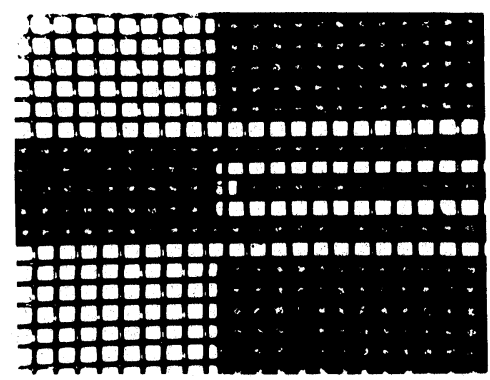

d) $90^{\circ}$

FIGURE 2 Mesh orientation for 325 S.S. -28 micron wire diameter. 


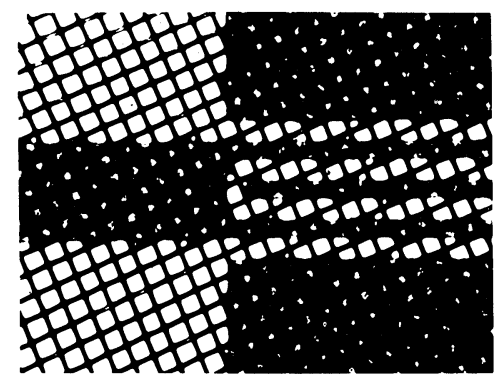

a) $221^{\circ}$

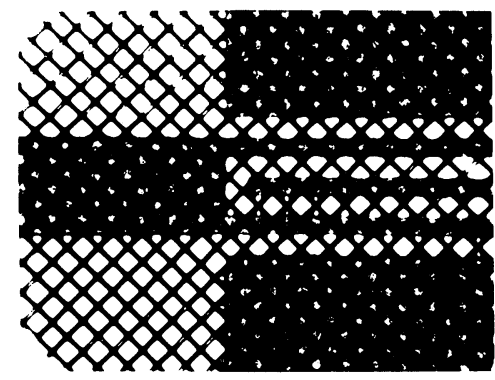

c) $45^{\circ}$

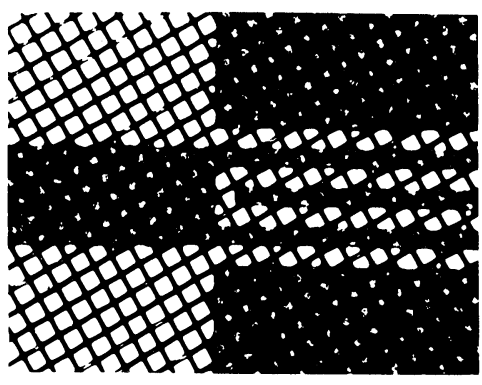

b) $30^{\circ}$

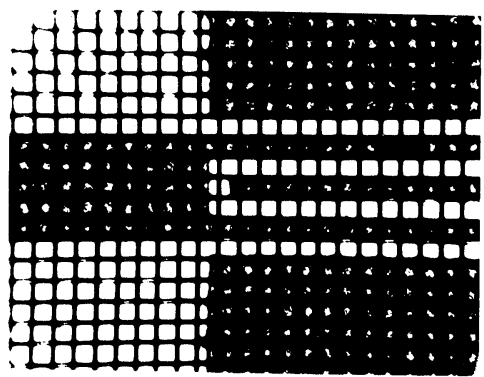

d) $90^{\circ}$

FIGURE 3 Mesh orientation for 325 S.S. - 23 micron wire diameter.

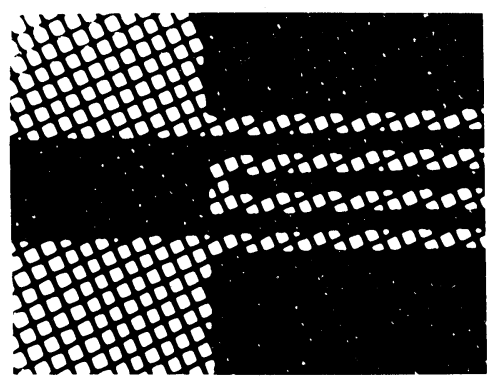

a) $22 \frac{1}{2^{\circ}}$

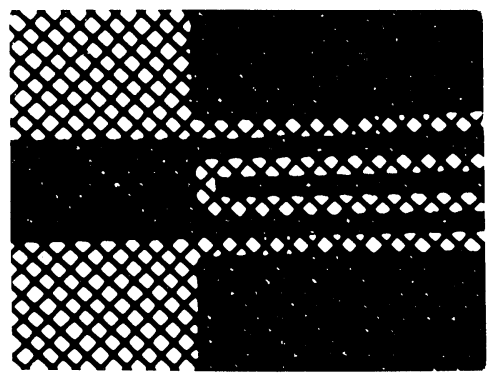

c) $45^{\circ}$

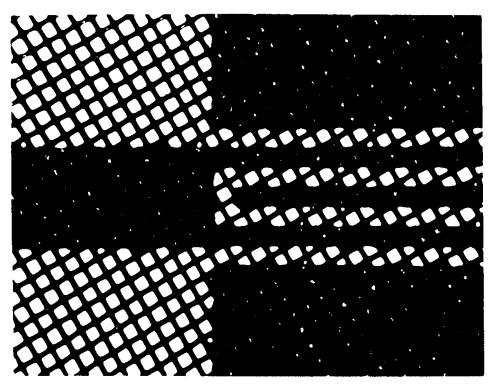

b) $30^{\circ}$

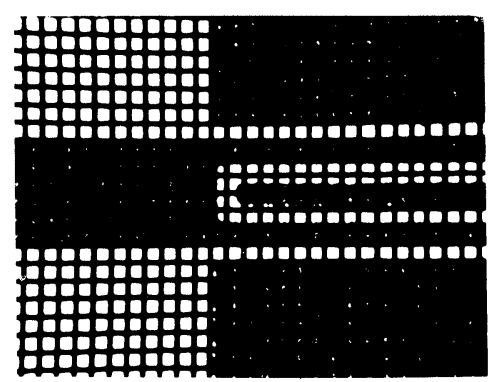

d) $90^{\circ}$

FIGURE 4 Mesh orientation for 400 S.S. -25 micron wire diameter. 


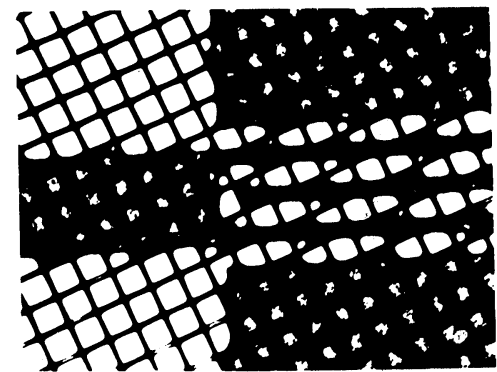

a) $2212^{\circ}$

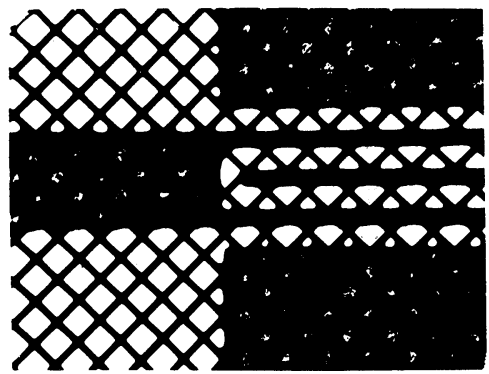

c) $45^{\circ}$

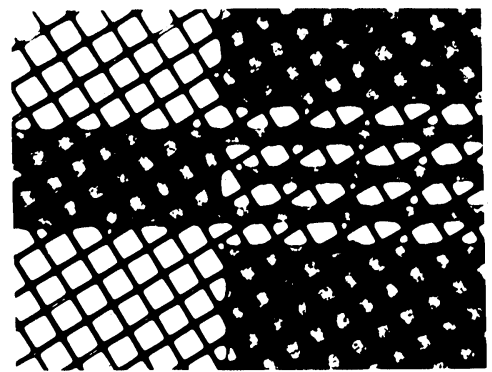

b) $30^{\circ}$

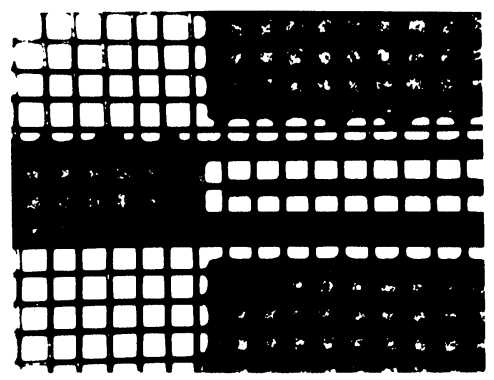

d) $90^{\circ}$

FIGURE 5 Mesh orientation for 230 S.S. -28 micron wire diameter.

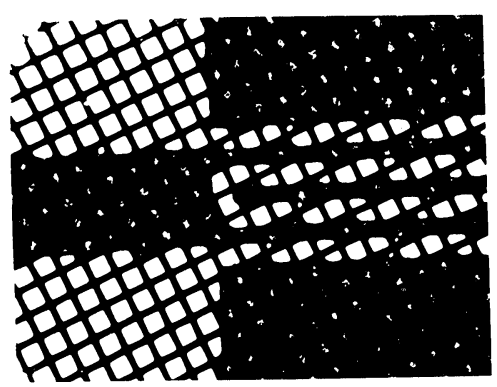

a) $221^{\circ}$

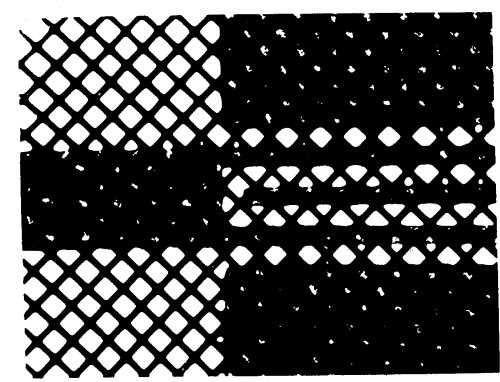

c) $45^{\circ}$

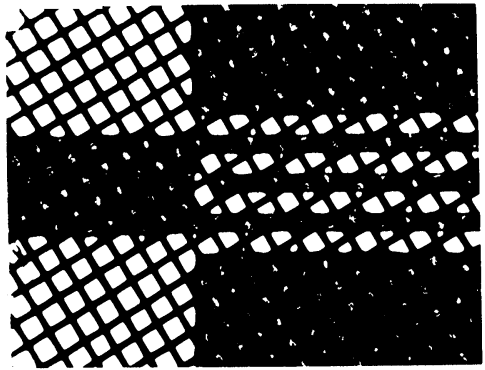

b) $30^{\circ}$

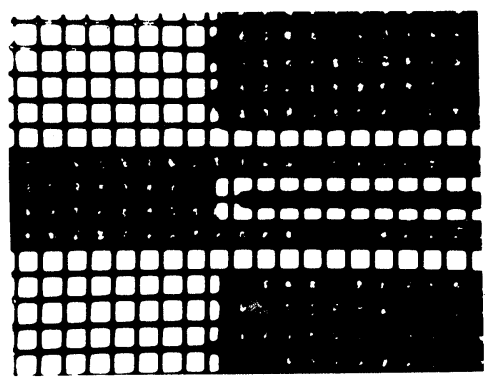

d) $90^{\circ}$

FIGURE 6 Mesh orientation for 280 S.S. - 30 micron wire diameter. 


\section{EMULSION}

The emulsion system selected for producing fine-line patterns on screens was required to have the following properties:
a) High resolution capability
b) Good solvent resistance
c) Good abrasion resistance
d) Reasonable shelf life in the unexposed state

Due to the popularity of screens to be precoated and stored in advance of their exposure, a minimum shelf life of 1 month was established for the emulsion system.

The smallest line width and spacing on the test pattern was 76 microns. The actual line width on the film positive (79 microns) was compared to the stencil opening on the screens and was found to vary depending upon how long the screen emulsion was exposed. Table III indicates the line opening in the screen as a function of exposure time for the 325 mesh screen (wire diameter of 28 microns).

Measurements were taken on the surface of the stencil. Attempts to measure the 79 micron line width in the plane of the mesh openings were unsuccessful since, in most cases, the edge of the line was not clearly defined. In order to maintain the resolution and line width of the stencil opening, some of the screens were slightly underexposed. However, it was evident that the greater the total thickness of the screen (mesh plus emulsion), the more the screen was underexposed during the 3 minute irradiation with the ultra-violet source. The test results for the five screens exposed for the same time are summarized in Table IV.

As indicated in Table IV, the correct exposure time for the screens is a function of both the mesh and the emulsion thickness. Screens having a greater weave thickness must be exposed longer unless the emulsion thickness is decreased accordingly. The most desirable procedure would be to decrease the emulsion thickness for the 230 and 280 mesh materials to improve the line width without underexposing the emulsion itself. Underexposed screens are not fully cured and will exhibit poorer solvent and abrasion resistance during printing. For the data in Table IV, the actual emulsion thickness was measured in each image location and recorded along with the total mesh-plus-emulsion thickness. The emulsion system utilized for these experiments did allow for good resolution of the 79 micron lines. However, several problems were encountered. There was a tendency for the emulsion to bridge between some of the individual wires or intersections of wires (knuckles) see Figure 5-d. The emulsion was difficult to remove from some of the more acute $\left.\left(22 \frac{1}{\circ}\right)^{\circ}\right)$ mesh openings as shown in all of the "a" illustrations of Figures 2-6.

The solvent resistance of the emulsion appeared to be good when tested with Butyl Cellosolve, Xylene, $1: 1: 1$ Trichloroethane, Isopropyl Alcohol, Freon-TE 35, and Methyl Ethyl Ketone. Acetone made the emulsion slightly tacky. Abrasion resistance was not evaluated since none of the screens were used in actual printing situations. The shelf life of the emulsion has only been tested to one month.

TABLE III

Line-width openings in the emulsion stencil as a function of emulsion thickness and exposure time

\begin{tabular}{|c|c|c|c|c|c|c|c|c|c|c|c|c|}
\hline \multirow[b]{3}{*}{$\begin{array}{l}\text { Mesh } \\
\text { count }\end{array}$} & \multicolumn{12}{|c|}{ Exposure times } \\
\hline & \multicolumn{3}{|c|}{3 Minutes } & \multicolumn{3}{|c|}{4 Minutes } & \multicolumn{3}{|c|}{5 Minutes } & \multicolumn{3}{|c|}{6 Minutes } \\
\hline & $\begin{array}{l}\text { Emul. } \\
\text { thick. }\end{array}$ & $\begin{array}{l}\text { Total } \\
\text { thick. }\end{array}$ & $\begin{array}{l}\text { Line } \\
\text { width }\end{array}$ & $\begin{array}{l}\text { Emul. } \\
\text { thick. }\end{array}$ & $\begin{array}{l}\text { Total } \\
\text { thick. }\end{array}$ & $\begin{array}{l}\text { Line } \\
\text { width }\end{array}$ & $\begin{array}{l}\text { Emul. } \\
\text { thick. }\end{array}$ & $\begin{array}{l}\text { Total } \\
\text { thick. }\end{array}$ & $\begin{array}{l}\text { Line } \\
\text { width }\end{array}$ & $\begin{array}{l}\text { Emul. } \\
\text { thick. }\end{array}$ & $\begin{array}{l}\text { Total } \\
\text { thick. }\end{array}$ & $\begin{array}{l}\text { Line } \\
\text { width }\end{array}$ \\
\hline 230 & 13 & 79 & 81 & 11 & 77 & 74 & 14 & 80 & $66^{*}$ & 11 & 77 & $64^{*}$ \\
\hline 280 & 12 & 86 & 81 & 17 & 91 & $74 *$ & 15 & 89 & $69 *$ & 17 & 91 & $64 *$ \\
\hline $325(28)$ & 11 & 72 & 79 & 13 & 74 & 71 & 11 & 72 & 64 & 11 & 72 & $61^{*}$ \\
\hline $325(23)$ & 13 & 64 & 79 & 14 & 65 & 71 & 13 & 64 & 66 & 11 & 62 & $53^{*}$ \\
\hline 400 & 15 & 71 & 81 & 16 & 72 & 74 & 15 & 71 & 69 & 15 & 71 & 66 \\
\hline
\end{tabular}


TABLE IV

Exposure results for various stainless steel screens with different total (Mesh + Emulsion) thicknesses. Exposure time for all screens was 3 minutes

\begin{tabular}{llllll}
\hline $\begin{array}{l}\text { Mesh } \\
\text { count }\end{array}$ & $\begin{array}{l}\text { Wire } \\
\text { diameter } \\
\text { (microns) }\end{array}$ & $\begin{array}{l}\text { Weave } \\
\text { thickness } \\
\text { (microns) }\end{array}$ & $\begin{array}{l}\text { Actual } \\
\text { Emulsion } \\
\text { thickness } \\
\text { (microns) }\end{array}$ & $\begin{array}{l}\text { Total } \\
\text { thickness } \\
\text { (microns) }\end{array}$ & $\begin{array}{l}\text { Exposure } \\
\text { results }\end{array}$ \\
\hline 230 & 28 & 66 & 13 & 79 & $\begin{array}{l}\text { Slightly } \\
\text { Underexposed }\end{array}$ \\
280 & 30 & 74 & 13 & 87 & Underexposed \\
325 & 28 & 60 & 13 & 73 & $\begin{array}{l}\text { Slightly } \\
\text { Underexposed } \\
325\end{array}$ \\
400 & 23 & 51 & 13 & 64 & Good \\
\hline
\end{tabular}

Additional data will be generated in the near future to determine the life expectancy of the unexposed screens.

\section{CONCLUSIONS}

Stainless steel wire cloth is a very desirable mesh material for fabricating fine-line stencil screens. The small diameter wires allow for relatively large mesh openings for the finer (higher mesh count) weaves.

Orienting the fine-line patterns to the mesh at angles other than $90^{\circ}$ is desirable in some cases. For very short conductor runs, it may be possible to align the pattern orthogonal to the screen so that the stencil pattern corresponds exactly with the mesh openings. However, in most situations, it is prudent to consider a pattern-to-mesh orientation of $22 \frac{1}{2^{\circ}}$, $30^{\circ}$, or $45^{\circ}$.

The emulsion material must be capable of resolving the fine-line images and also withstand the rigors of the printing process. With the correct emulsion thickness and exposure time, the proper combination of mesh and emulsion will yield precise stencil screens for printing fine-line images.

\section{REFERENCES}

1. Charles A. Harper, Handbook of Thick Film Hybrid Microelectronics, McGraw Hill, New York 1974 chapter 2.

2. F. Franconville, K. Kurzweil, and S. G. Stalnecker, Screen: Essential Tool for Thick Film Printing, Solid State Technol. (Oct. 1974) 61-68.

3. P. J. Griffin, and S. G. Stalnecker, Screen Fabrication for Fine Line Printing, International Microelectronics Conf. (June 1976) 30-36. 

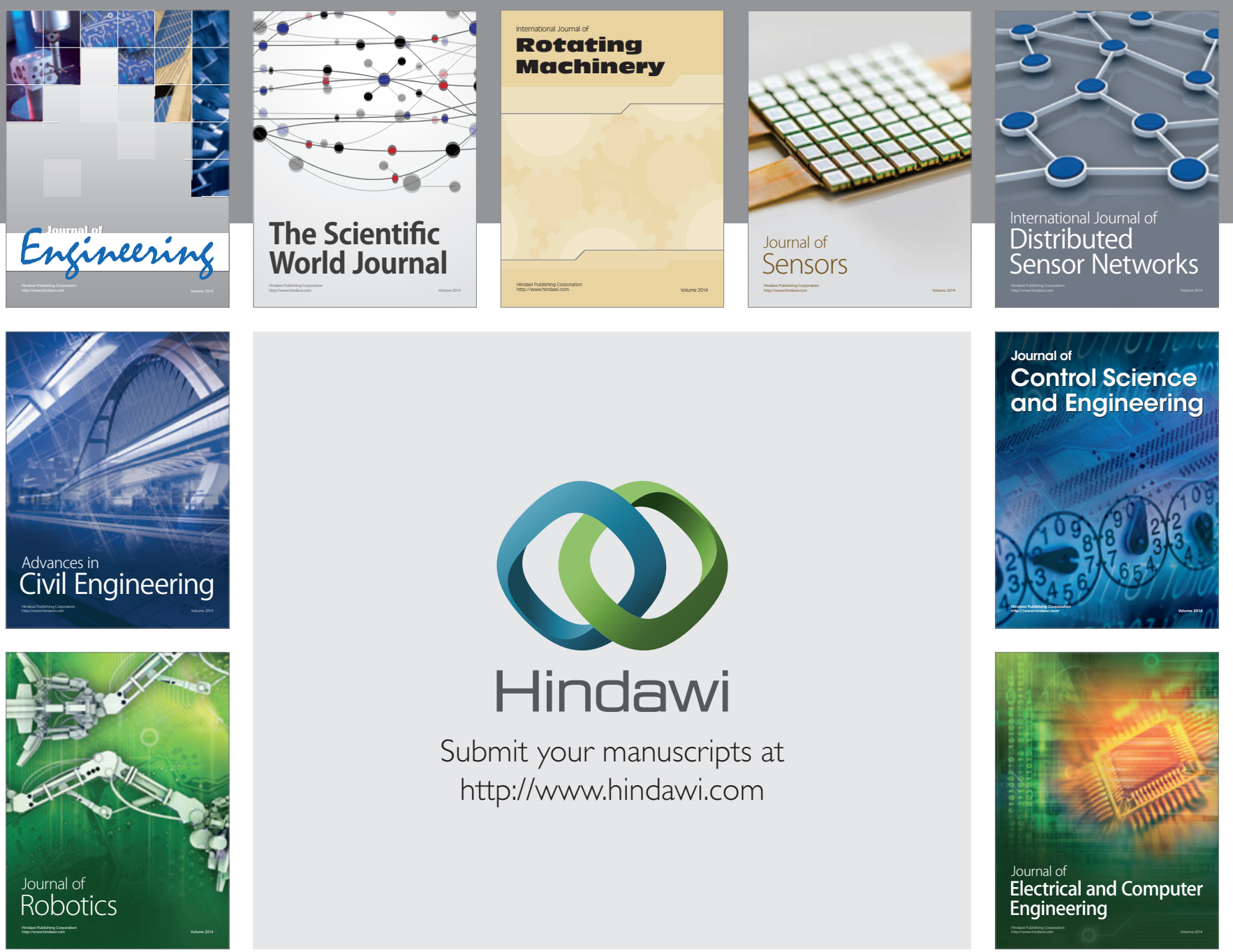

Submit your manuscripts at

http://www.hindawi.com
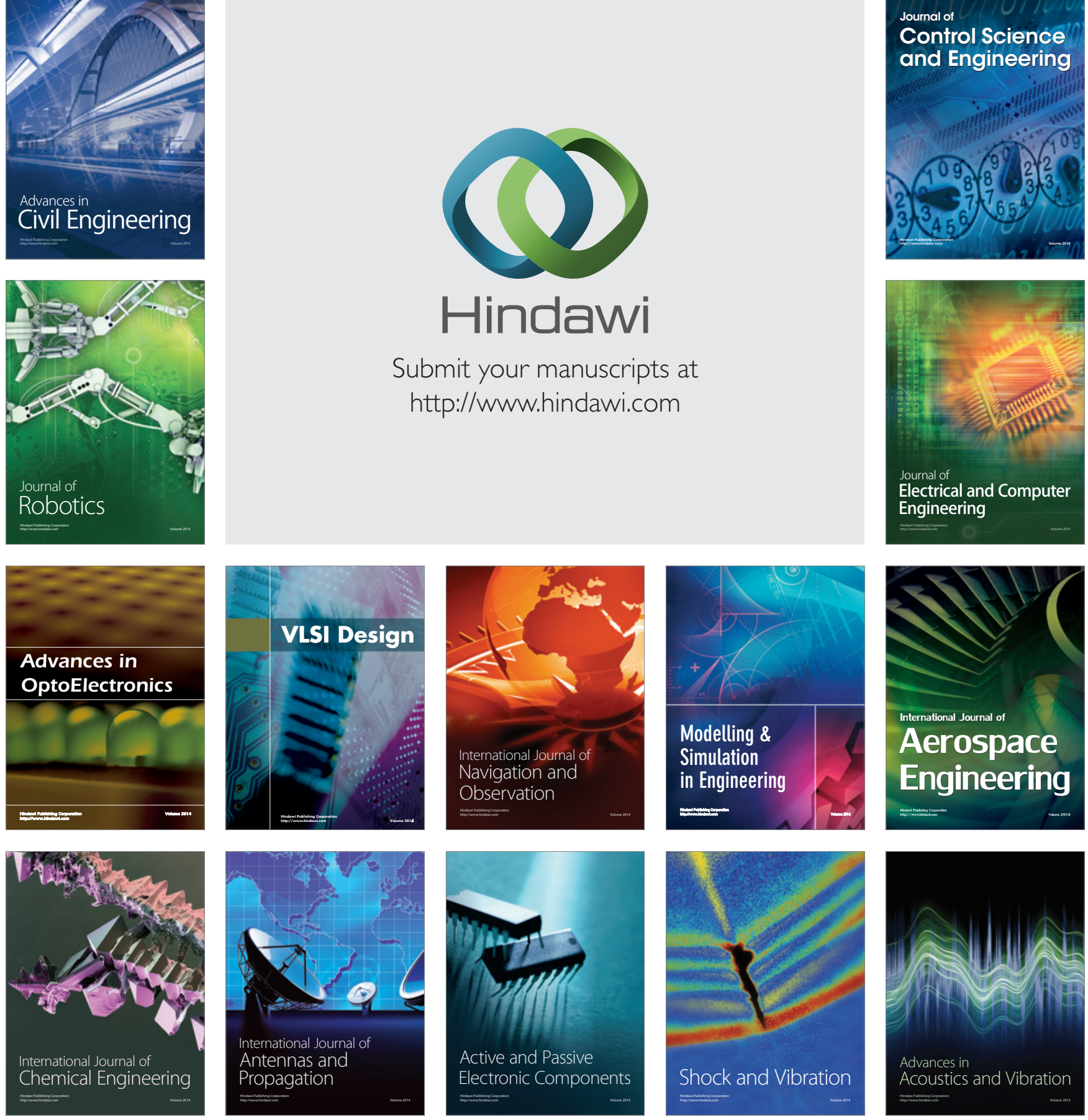